\title{
Physical Properties of the Polar Winter Mesosphere Obtained From Low-Frequency Propagation and Partial Reflection Studies ${ }^{1}$
}

\author{
J. S. Belrose, L. R. Bodé, and L. W. Hewitt \\ Contribution From Defence Research Telecommunications Establishment, Ottawa, Ontario, Canada
}

(Received July 20, 1964; revised August 11, 1964)

\begin{abstract}
During the winter of 1963-64 observations of partial reflections at a frequency of 2.66 $\mathrm{Mc} / \mathrm{s}$ were made at Resolute Bay (invariant magnetic latitude $841^{1}{ }^{\circ}$ ) near local midnight. Utilizing the different amplitudes of the ordinary and extraordinary backscattered waves, information was obtained about electron densities and electron collision frequencies. Electron densities range from $10 \mathrm{~cm}^{-3}$ at $80 \mathrm{~km}$ to $1000 \mathrm{~cm}^{-3}$ at $110 \mathrm{~km}$. Collision frequency values are a factor of 2-4 times greater than average daytime results at lower latitudes. These observations, together with some indirect inferences based on low frequency propagation between Thule and Churchill (invariant magnetic latitude $7912^{\circ}$ at path midpoint) are discussed and it is concluded that (1) galactic cosmic rays are responsible for electron production below $90 \mathrm{~km},(2)$ ionization rates in excess of galactic cosmic ray production are required for heights above $90 \mathrm{~km}$, (3) effective electron loss rates below $90 \mathrm{~km}$ are markedly more rapid than dissociative recombination, and (4) the polar winter mesosphere is hotter than previous data suggest.
\end{abstract}

\section{Introduction}

The Radio Physics Laboratory has during several years been making studies of the high latitude $D$ region by the propagation of low-frequency radio waves and the partial reflection of medium frequency pulses from ionization irregularities within the region. The results so far reported [Belrose and Burke, 1964; and Belrose and Hewitt, 1964], were obtained by the method of partial reflection, at Ottawa $(L=3.6$ or invariant magnetic latitude $58.2^{\circ}$ ). There have been only a few studies of the lower ionosphere at latitudes above the auroral zone $(L>10$ or invariant magnetic latitude $>711^{1 / 2}$ ). In one of these [Gregory, 1962], partial reflections of MF radio waves were made at Scott Base, Antarctica $\left(79^{\circ} \mathrm{S}\right.$ geomagnetic latitude). From an analysis of partial reflection data and Forbush decreases in the flux of galactic cosmic rays, Gregory attempted to show that the residual ionization during the polar night on undisturbed days was due to galactic cosmic rays, although his estimated electron densities, according to present estimates of electron loss rates, required ionization rates in excess of cosmic-ray production.

During the winter of 1963-64, observations of partial reflections at a frequency of $2.66 \mathrm{Mc} / \mathrm{s}$ were made at Resolute Bay, Cornwallis Island, N.W.T. $\left(L \simeq 100\right.$ or invariant magnetic latitude $\left.841_{4}^{\circ}\right)$. Utilizing the different amplitudes of the ordinary and extraordinary backscattered waves, information is obtained about electron densities and electron col-

\footnotetext{
1 This paper was presented at the USNC-URSI/IEEE meeting 15-18 April 1964 $\mathrm{n}$ Washington, D.C.
}

lision frequencies. The experimental technique and method of analysis [Belrose and Burke, 1964], and the experimental equipment employed in the study [Belrose et al., 1964] have been previously described, and will not be discussed here. These observational data differ from those of Gregory, who observed partial reflections with linearly polarized antennas and could therefore only make estimates of the electron densities from the received echo amplitude versus height data.

This paper gives the results of an analysis of partial reflection observations made near local midnight during the middle of the polar winter. These data are discussed in the light of present knowledge of lower ionosphere processes. The paper begins with a description of some studies of very high latitude lowfrequency propagation, since these data reveal some interesting features about changes in the electron densities near the base of the ionosphere.

\section{Low-Frequency Propagation Studies}

The field strengths of $\mathrm{CW}$ transmissions, at frequencies of about $80 \mathrm{kc} / \mathrm{s}$ propagated to distances of about $2000 \mathrm{~km}$, have been routinely recorded, since the summer of 1960 , for a number of circuits extending over a range of latitudes in Canada. These recordings have shown that when the LF transmission path lies entirely within the polar cap, i.e., over transmission paths inside the auroral zone or at geomagnetic latitudes $>70^{\circ}$, the daily variations in field strength are quite different from those for similar transmissions at lower latitudes. 
The experimental observations with which we are concerned are the recordings of the USAF 77.15 $\mathrm{kc} / \mathrm{s}$ transmissions from Thule, which are recorded at Fort Churchill at a distance of $2210 \mathrm{~km}$. The midpoint of this path is at $L \sim 30$ or invariant magnetic latitude of $79.5^{\circ}$. Figure 1 shows typical undisturbed diurnal variations of field strength for winter (January), equinox (March), and summer (July), at midmonth. Some individual days vary widely in detail from these typical variations, but in general the variations for undisturbed days are more regular than those recorded at lower latitudes. The times for solar zenith angles of $102^{\circ}, 98^{\circ}, 94^{\circ}$, and $86^{\circ}$, as well as ground sunrise (SR) and sunset (SS) at $90^{\circ} 50^{\prime}$, are shown by short vertical bars. The following features of these data are worth discussion:

(1) The $D$-region is always sunlit in summer $\left(\chi<86^{\circ}\right)$, so that no strong diurnal variation is evident.

(2) There is a marked diurnal asymmetry (particularly clear in this figure during March), in that the main decrease in field strength before sunrise occurs in about $3 / 4 \mathrm{hr}$, for solar zenith angles between $101^{\circ}$ and $97^{\circ}$, whereas after sunset it takes more than $4 \mathrm{hr}$ for the field strengths to reach their presunrise values. LF propagation studies over paths of similar length at lower latitudes show a fairly abrupt onset of nighttime propagation conditions for solar zenith angles greater than $102^{\circ}$.

(3) And finally, the nighttime recordings exhibit only shallow fading.

In figure 2 signal amplitudes for several transmissions (for circuits as marked) recorded during an undisturbed night are shown. The large nocturnal irregular variation of field strength is clearly evident for all transmissions, except the Thule-Churchill path. These recordings show a small disturbance, observed for the paths near the auroral zone ( $L$ between $4 \frac{1}{2}$ and 9 ), which shows in the recording's as a rapid fluctuation of field strength for a period of about an hour (0815-0915 U'T). Larger disturbances also affect lower latitude paths, but not in general the Thule-Churchill path. Large nocturnal signal amplitude decreases, lasting an hour or so, are sometimes observed on this transmission. These have not yet been correlated with other geophysical data. They are not in general observed at lower latitudes.

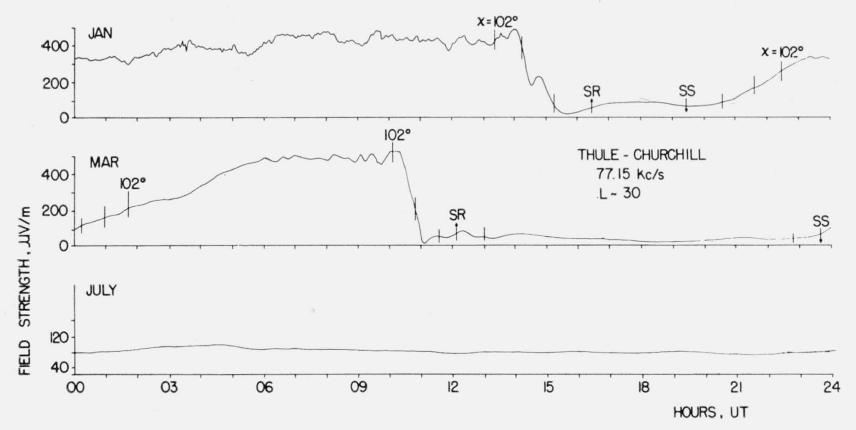

- Figure 1. Low frequency field strengths observed at Churchill from a $7 \% .15 \mathrm{kc} / \mathrm{s}$ transmitter at Thule.

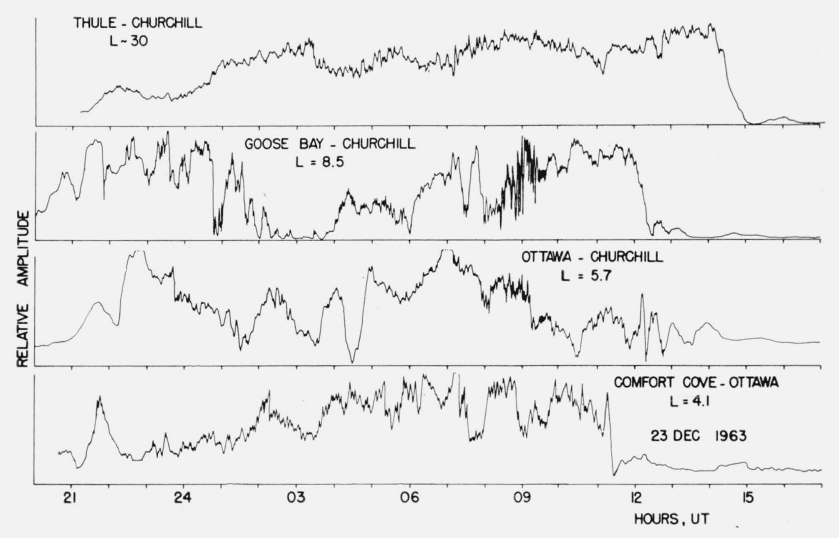

Figure 2. Low frequency (70 to $80 \mathrm{kc} / \mathrm{s}$ ) field strengths for an undisturbed night for various transmissions as marked.

During solar proton events, the nocturnal signal amplitude on this circuit becomes weaker, and the fading even less pronounced. Signal strength reductions have been observed for as long as 15 days after a series of major solar proton events [Belrose and Ross, 1962]. The nocturnal LF amplitudes of high latitude transmissions are in fact a most sensitive method of detecting the presence of solar protons in the ionosphere.

Time variations associated with Forbush decreases of cosmic radiation have not yet been looked for. Nevertheless, the sensitivity of the data to solar proton influxes, and the quasi-constant nocturnal field strengths, has led [Belrose, 1963] to the suggestion that protons are responsible for electron production at low heights under both undisturbed and disturbed conditions. The marked diurnal asymmetry suggests that there are important differences at high latitudes in electron decay processes compared with middle latitudes, but without the more direct observational data of electron density as deduced by partial reflection over sunrise and sunset, this feature of the low-frequency propagation data cannot be directly interpreted.

\section{Partial Reflection Experiment}

\subsection{Experimental Observations}

The partial reflection data made at Ottawa have not so far given information about the nighttime lower ionosphere, because of high nighttime noise and station interference levels. The noise levels at Resolute Bay are very low, even at night, and partial reflection observations can be made on most days. Figure 3 shows data for the received echo amplitudes versus height for the two magneto-ionic components $A x$ and $A o$ made on a particular low noise night, the 2 January 1964, compared with the average data for $A o$ observed on nine undisturbed nights during: 22 December 1963 to 4 January 1964. These data are judged to represent undisturbed conditions on the basis of the Thule-Churchill LF transmissions and the Resolute Bay ionosonde data. Data for 4 


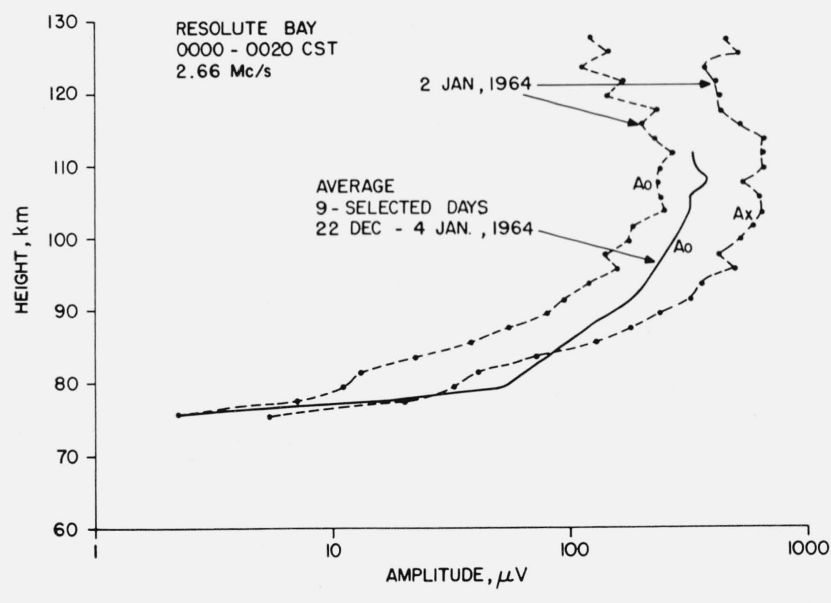

Figure 3. Amplitude of ordinary and extraordinary backscattered waves with height measured at Resolute Bay.

days were not included in the average because of the presence of sporadic- $E$, which showed on our recording's as a rapid increase in echo strengths to off-scale values for heights greater than 90 to $100 \mathrm{~km}$ and as regular Es traces on the routine ionograms made by the Department of Transport operated ionospheric sounder at Resolute Bay.

These observations were made near local midnight, during a time of the year when the lower ionosphere had not been illuminated by solar ultraviolet radiations for about $1 \frac{1}{2}$ months. The minimum solar zenith angle at local midday was not less than $98^{\circ}$ for the period of the observations. In the absence of a nocturnal electron production, therefore, the electron densities would have decayed to very low number densities.

Figure 4 shows the average amplitude ratio $A x / A$ o for the nine undisturbed nights. The points plotted are the three point running average of mean data. $A x / A o$ first increases with height, over a height range 75 to $87 \frac{1}{2} \mathrm{~km}$. It is this part of the curve which provides a measure of electron collision frequency, since differential absorption is negligible. Above $87 \frac{1}{2} \mathrm{~km}$ differential absorption begins, and $A x / A o$ sharply decreases. It is this part of the curve which gives a measure of electron density.

\subsection{Electron Collision Frequency}

Figure 5 shows values of collision frequency deduced from the observational data just discussed, i.e., for the 2 January 1964, and the 9 average days, compared with data measured at lower latitudes, at various times and by various methods. The Resolute Bay values for collision frequency are markedly greater than the range of values measured at lower latitudes. The values for 2 January are about 2 times greater, and the average values are about $4 \frac{1}{2}$ times greater, than those given by the continuous curve, which has been calculated using laboratory determined relations between collision frequency and

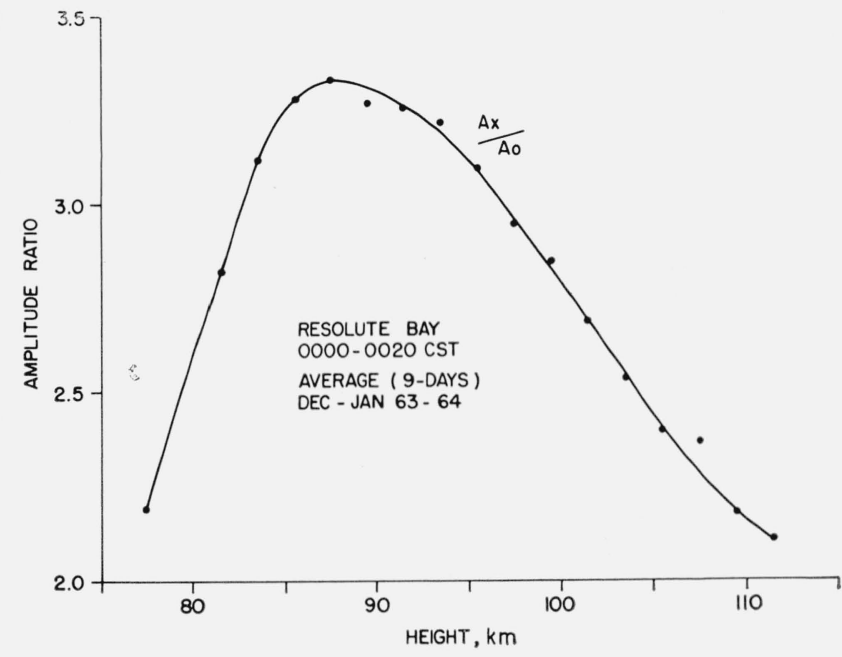

Figure 4. Amplitude ratio Ax/Ao with height measured at Resolute Bay.

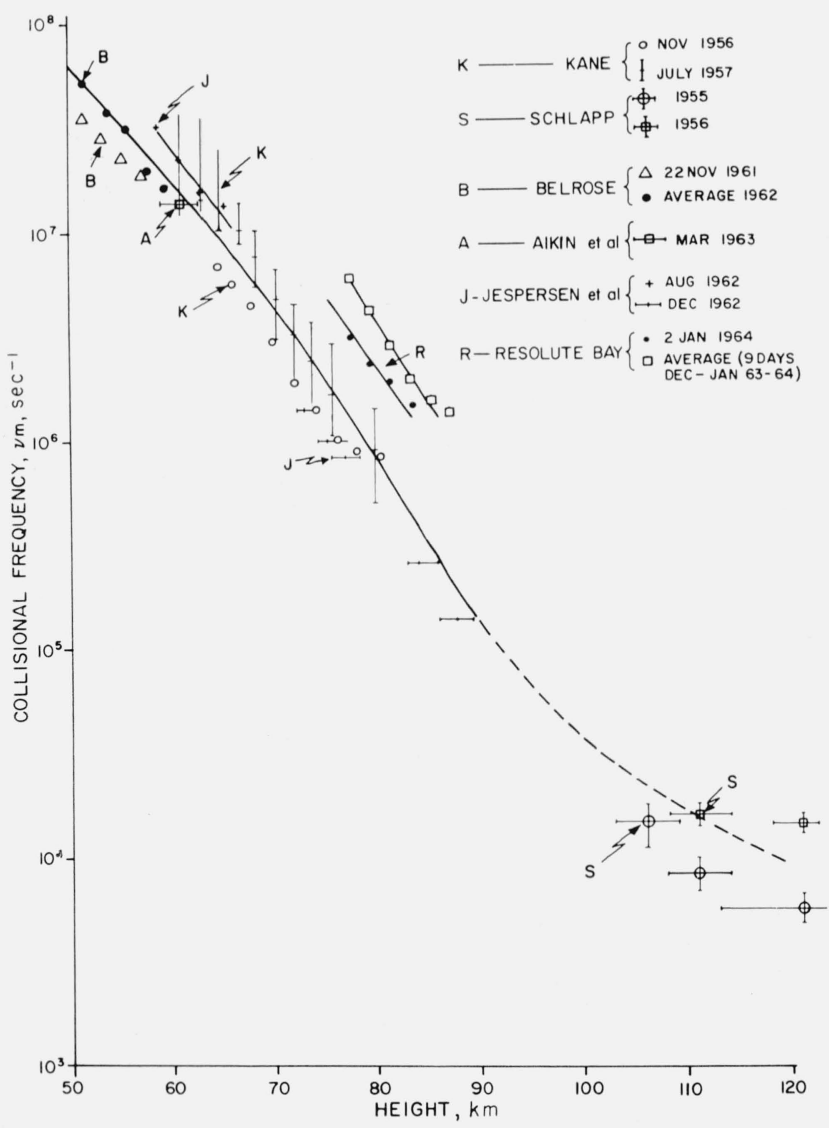

FIguRE 5. Collision frequency of monoenergetic electrons with height measured at Resolute Bay compared with various data (see Belrose and Hewitt, 1964). 
particle number density and temperature, and the COSPAR International Reference Atmosphere (CIRA 1961). The calculated curve is in reasonable agreement with the average results at middle latitudes.

It should be stressed, at this point, that the experimental measurements of partial reflection show a difference between low and high latitudes in the ratios for $A x / A o$ in a height range where differential absorption is negligible. The ratio between the reflection coefficients for the two magneto-ionic components, on the assumption that the scatter is from a turbulent region irregular in electron density, is determined by electron collision frequency, but independent of the actual electron density [Belrose and Burke, 1964]. On this assumption the observed ratios are interpreted to mean a difference in collision frequency.

\subsection{Electron Density}

Figure 6 shows the average electron density-height curve deduced from the observational data, compared with calculated electron density-height curves by Webber [1962], which are discussed in the next section. The measured data, shown in the upper part by the continuous curve, give electron density values deduced from the measured different amplitudes $A x$ and $A o$ in the height range where differential absorption is measurable; and the lower broken curve assumes, with reasonable theoretical justification [Belrose and Burke, 1964], that the electron density, in the height range where differential absorption is negligible, is proportional to the O-mode echo amplitude.

\section{Discussion}

Detailed examination of figures 5 and 6 show that there are marked differences between electron collision frequency and electron density in the polar winter mesosphere from those expected. Let us first discuss the differences in collision frequency.

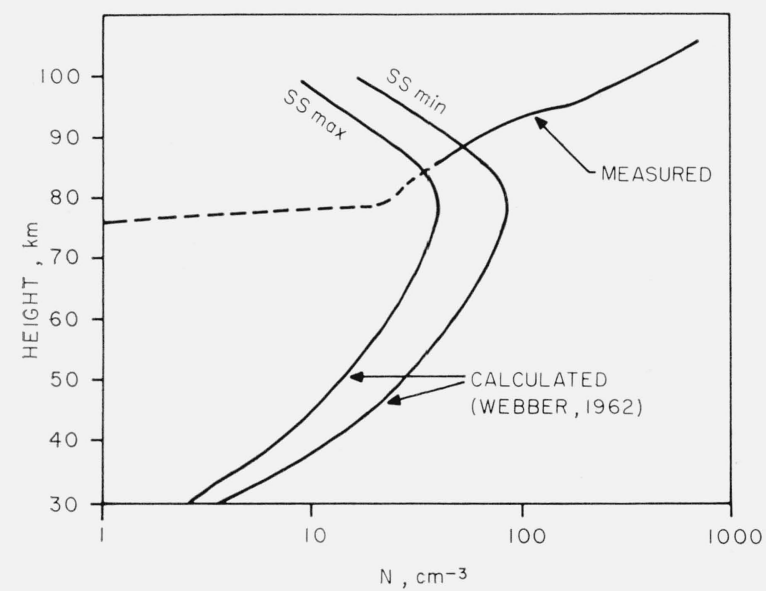

Figure 6. Midnight electron density-height curves measured at Resolute Bay, compared with calculated curves assuming electron production by galactic cosmic rays for geomagnetic latitudes > ${ } 0^{\circ}$ and maximum and minimum epoch of the solar cycle.
It is already fairly well established that the polar winter mesopause region is warmer than the CIRA reference atmosphere model, by some 40 to $60^{\circ} \mathrm{K}$ [Murgatroyd, 1957], and this warming is variable from day-to-day. There are meteorological phenomena which could account for the amount of expected heating (e.g., chemical heating by recombination of atomic oxygen, Kellogg [1961], Young and Epstein [1962], and Maeda [1963]; or dynamic heating by atmospheric acoustic waves from the polar night jet stream [Maeda, 1964], and by turbulence or internal gravity waves [Hines, 1963]. On the assumption that the pressures at the $20 \mathrm{~km}$ level are not different from the CIRA model, the local gas densities, even with heating, will also not be different in the polar winter mesopause region. The temperature difference alone can account for an increased collision frequency by about a factor of 1.3. The observed larger differences, by a factor of 2 to 4 , cannot therefore be explained on the basis of present estimates of mesopheric heating. It seems probable, therefore, that:

(1) The polar winter mesopause region is hotter than previously thought, and or

(2) The electron and gas temperatures are not equal.

We have already suggested [Belrose and Hewitt, 1964] that other experimental evidence suggests that the electron and gas temperature in the mesosphere might not be equal (at least during the day). 'This suggestion is new, and is not yet theoretically justifiable. There is clearly a need for in-situ measurements by rockets of the gas pressures and temperatures in the polar winter mesosphere.

The marked differences between the theoretically computed electron densities, and the measured electron densities, also warrant discussion. The calculated curves, shown in figure 6 , have been computed by Webber [1962], and are for nighttime, at latitudes $>70^{\circ}$ geomagnetic, for two epochs of the solar cycle. The calculations assume that electron production is by galactic cosmic rays. There are marked differences at both low and high heights in the mesosphere between the calculated and measured electron densities. The absence of measurable electron densities below $75 \mathrm{~km}$ might be because of an absence of turbulent scatterers, but the rapid increase above this height suggests that there are indeed few electrons at low heights.

On the assumption that galactic cosmic rays are the sole electron production mechanism for heights below about $90 \mathrm{~km}$, detailed examination of the available data suggests that there is a marked difference between electron loss processes at $90 \mathrm{~km}$ and $80 \mathrm{~km}$ and that this difference may be attributed to the formation of negative ions at the lower height. The measured electron density at $90 \mathrm{~km}$, taken together with Webber's curve for the rates of ion production at geomagnetic latitudes $>70^{\circ}$ and the minimum epoch of the solar cycle, yields an "effective" recombination loss rate of about $1.2 \times 10^{-7} \mathrm{~cm}^{3} \mathrm{sec}^{-1}$. This may be compared with a value of $1 \times 10^{-7} \mathrm{~cm}^{3} \mathrm{sec}^{-1}$ between 88 and $95 \mathrm{~km}$ deduced from experiments 
carried on a rocket at Fort Churchill in 1963. Adey et al. [1964] measured, during an auroral absorption event, the ambient electron density at the rocket. McDiarmid and Budzinski [1964] measured electron flux as a function of altitude at certain energies above $10^{4} \mathrm{eV}$, from which they could compute the ionization production rate. Using the measured free electron densities, and the computed ionization production, the "effective" recombination loss rate was computed. The apparent agreement between the two sets of different data give support to the suggestion of a cosmic ray production below $90 \mathrm{~km}$, and, further suggest that at $90 \mathrm{~km}$ there is negligible loss of electrons to form negative ions, i.e., the electron removal process is one of dissociative recombination, which is currently thought to have a rate coefficient in the $D$-region of about $2 \times 10^{-7} \mathrm{~cm}^{3} \mathrm{sec}^{-1}$ [Reid, 1964].

Similar computations for a height of $80 \mathrm{~km}$ yield a loss rate of about $6 \times 10^{-5} \mathrm{~cm}^{3} \mathrm{sec}^{-1}$, which may be compared with the rocket results (extrapolated below $83 \mathrm{~km}$ ) of about $10^{-4} \mathrm{~cm}^{3} \mathrm{sec}^{-1}$. The Resolute data and the Churchill rocket data agree within a factor of two, and both are considerably larger than the "minimum" nighttime loss rate of about $10^{-6} \mathrm{~cm}^{3}$ $\mathrm{sec}^{-1}$ at $80 \mathrm{~km}$ obtained by using a "maximum" collisional detachment rate [Crain, 1961] or the value of about $1.6 \times 10^{-6} \mathrm{~cm}^{3} \mathrm{sec}^{-1}$ deduced by Webber [1962].

The calculated electron densities at low heights in the mesosphere depend very heavily on the collisional detachment coefficient for $\mathrm{O}_{2}{ }^{-}$. The value used by Webber of $2 \times 10^{-17} \mathrm{~cm}^{3} \mathrm{sec}^{-1}$, which is something like the Bailey and Branscomb [1960] value deduced from polar cap absorption, is 500 times larger than the Phelps and Pack [1961] laboratory measurements which gave $6 \times 10^{-20} \mathrm{~cm}^{3} \mathrm{sec}^{-1}$ for $\mathrm{O}_{2}{ }^{-}$at $230{ }^{\circ} \mathrm{K}$. Using this latter value would give much lower electron densities [Crain, 1961; Arnold, 1964]. Crain has emphasized that for negligible detachment "effective electron loss rate" has no meaning. The values given for $80 \mathrm{~km}$ height in the preceding paragraph are not therefore strictly correct.

The apparent agreement between the rocket data and the Resolute data, which are for quite different ionization processes and ionization rates are taken to mean (1) the undisturbed nighttime electron densities below $90 \mathrm{~km}$ can reasonably be accounted for by ionization by galactic cosmic rays, and (2) there is a rapid change in the way electrons are lost at $80 \mathrm{~km}$ compared with $90-\mathrm{km}$ heights, and this difference might be associated with a large change in the effective role of negative ions at the two heights.

The height range 90 to $100 \mathrm{~km}$ poses other problems. Some additional source of ionization is required, which might be electron fluxes in the $10^{4}-$ $10^{5} \mathrm{eV}$ energy range. The electron fluxes required are very small, some $10 \mathrm{~cm}^{-2} \mathrm{sec}^{-1}$ sterad $^{-1}$ [Gregory, 1962], which are well below the threshold of existing rocket and satellite detectors. These fluxes must be arriving quite uniformly with time; recall the quasi-constant nocturnal field strength of LF propagation.

It is hoped that observations over sunrise and sunset, which have been made at Resolute Bay during March 1964, and which are currently being analyzed, will provide results pertaining to the above discussion.

We thank G. Oczkowski who made the partial reflection experimental observations at Resolute Bay, and Mrs. J. Thibault who scaled the data.

\section{References}

Adey, A. W., W. J. Heikkila, and W. K. Lacey (1964), to be published.

Arnold, Helen R. (1964), Collisional detachment and the formation of an ionospheric $\mathrm{C}$ region by $\mathrm{E}$. T. Pierce, Radio Sci. J. Res. NBS/USNC-USRI 68D, No. 2, 215-217.

Bailey, D. K., and L. M. Branscomb (1960), Rate coefficient for $\mathrm{O}_{2}^{-}$collisional detachment, Bull. Am. Phys. Soc. (2) 5, 123 .

Belrose, J. S. (1963), Present knowledge of the lowest ionosphere, AGARDograph 74, Propagation of radio waves at frequencies below $300 \mathrm{kc}, \mathrm{pp} .3-23$, ed. W. T. Blackband (Pergamon Press, Oxford, London).

Belrose, J. S., and M. J. Burke (1964), Study of the lower ionosphere using partial reflection, Part I. Experimental technique and method of analysis, J. Geophys. Res. 69, No. 13, 2799-2818.

Belrose, J. S., and L. W. Hewitt (1964), Variation of collision frequency in the lowest ionosphere with solar activity, Nature 202, 267-269.

Belrose, J. S., and D. B. Ross (1962), Observations of unusual low frequency propagation made during polar cap disturbance (PCD) events, J. Phys. Soc. Japan 17, Supp. A-I, 127.

Belrose, J. S., L. R. Bodé, L. W. Hewitt, and J. M. Griffin (1964), An experimental system for studying partial reflections from the lower ionosphere, DRTE Report No. 1136.

Crain, C. M. (1961), Ionization loss rates below $90 \mathrm{~km}$, J. Geophys. Res. 66, $1117-1126$.

Gregory, J. B. (1962), Residual ionization in the polar lower ionosphere, J. Geophys. Res. 67, 3829-3841.

Hines, C. O. (1963), The upper atmosphere in motion, Quart. J. Roy. Meteorol. Soc. 89, 1.

Kellogg, W. W. (1961), Chemical heating above the polar mesopause in winter, J. Meteorol. 18, 373-381.

Maeda, K. (1963), Auroral dissociation of molecular oxygen in the polar mesosphere, J. Geophys. Res. 68, 185.

Maeda, K. (1964), On acoustic heating of the polar night mesosphere, J. Geophys. Res. 69, 1381.

McDiarmid, I. B., and E. E. Budzinski (Nov. 1964), Angular distributions and energy spectra of electrons associated with auroral events, Can. J. Phys. 4\%.

Murgatroyd, R. J. (1957), Winds and temperatures in the 20-100 km region-a review, Quart. J. Roy. Meteorol. Soc. 83, 417.

Phelps, A. V., and J. L. Pack (1961), Collisional detachment in molecular oxygen, Phys. Rev. Letters 6, 111-113.

Reid, G. C. (1964), Physical processes in the $D$ region of the ionosphere, Rev. Geophysies 2, 311-333.

Webber, W. (1962), The production of free electrons in the ionospheric $D$ layer by solar and galactic cosmic rays and the resultant absorption of radio waves, J. Geophys. Res. 67, 5091-5106.

Young, C., and E. S. Epstein (1962), Atomic oxygen in the polar winter mesosphere, J. Atmospheric Sci. 19, 435-443.

(Paper 68D12-436) 